\title{
Research on the ways of cultivating students' professional quality in Higher Vocational Education
}

\author{
Tian Jing, Gong Pijuan, Zhang Liping
}

Wei Fang Vocational College, Weifang Shandong, 261041, China

Keywords: Higher vocational education; Higher vocational students; Professional quality

\begin{abstract}
The essence of occupation literacy refers to the sum of human occupation occupation skills and ethics, including occupation consciousness, occupation morals, some aspects of occupation habits and occupation skills. Higher occupation education is carried out in China has been very extensive, vocational college students in the degree of disadvantage, often in a very passive position in the job market, which requires the higher vocational colleges in knowledge and education at the same time, also to strengthen the training of occupation accomplishment. With the progress of the times and social development, human resources market competition becomes more intense, every occupation person must enhance their occupation accomplishment, in order to ensure their own in the competition In a good position for the fierce market environment.
\end{abstract}

\section{The necessity and significance of Higher Vocational Students' professional accomplishment training}

The higher occupation education is an important part of the education system, from the point of view of the world, the higher occupation education time officially launched in China is relatively late, but the momentum of development is very rapid, the colleges of higher occupation education in our universities occupies a very large proportion of higher occupation colleges mission. Is mainly to cultivate talents for the social production, and the ordinary university in academic research mainly are very different, higher vocational college students is directly to the society and the characteristics of the enterprise culture, the enterprise usually requires complex social talent, which requires higher occupation colleges must strengthen the occupation literacy training of higher vocational students ability The higher occupation education degree. With the occupation of very distinct characteristics, the need for training in specific industry or occupation, first in the education practice, should pay attention to emphasize the occupation skills, but for higher vocational students only have excellent occupation skill is not able to guarantee their competitiveness, also need to better occupation accomplishment, in order to ensure their own human resources in the market place.

Our country occupation education has some problems, the causes of these problems are in many aspects. First, from the development of higher occupation education of our country, because of the overall development time is short, so also in the teaching purpose and mode of education above is not particularly clear, during the period of school education just mastered certain the occupation skills of higher vocational students, and there is a big gap compared with the students in the occupation literacy and ordinary colleges. Secondly, vocational college students is aimed at social and enterprise culture, the cultivation of the direction is very clear, but from the current education, due to the lack of education system, schools and enterprises often fail The direct combination of industry, which resulted in the higher vocational college students tend to grasp the theoretical knowledge more, but only in the working process of the occupation skill is not enough, this is not a kind of occupation accomplishment outstanding performance. Thirdly, due to the higher occupation colleges in education tend to be relatively limited, so the process of educational practice cannot set more practical courses, occupation orientation of higher vocational students is a practical and technical personnel, need more experimental and training courses, in order to better grasp the occupation skills. The above three aspects of the problem in the practice of higher occupation education of current our country is particularly prominent, as the cause of the current high The main 
causes of vocational students occupation ability is the occupation of higher vocational students to improve literacy, we should first consider starting from solving these problems.

\section{The significance of vocational quality training of Higher Vocational Students}

Higher vocational education is a kind of occupation education after all, so the most direct teaching purpose is for students to solve the employment problem, to obtain the corresponding work must have the corresponding occupation in the field of occupation ability, the occupation ability is also included in the occupation literacy category. With the flourishing development of our country occupation education, the increasing number of Higher Vocational Colleges Students in the job market, the employment pressure of competition will naturally become more and more, and the competition is the core talent occupation literacy competition, many enterprises in the selection of personnel, will be listed in the first occupation literacy factors, so to strengthen the occupation literacy training of higher vocational students ability Degree, has a very important significance to improve the core competitiveness in the job market. China's current economic development is facing a big slowdown pressure, the adjustment of industrial structure and supply side reforms and a series of economic reform policy implementation, objectively created many kinds of undergo personnel, these people will have a big part to re engage in employment market competition, this is for higher vocational students in the human resources market will form a certain impact, for the construction of harmonious society will also bring some challenges, which requires the occupation education should be expanded, not only for young students. For training, for some social personnel access channels should also be wider. All in all, strengthen the occupation literacy training efforts for higher vocational students of great significance, but also is important for the construction of a harmonious society.

\section{The approach to cultivating occupation quality of College Students}

\subsection{Establish the scientific quality view of occupation}

The higher occupation education practice in our country, there is excessive pursuit of theory and technology ability training, and to cultivate the concept of occupation literacy is not enough, which for the employment of higher vocational students and the overall occupation is detrimental to the development, need to establish in the future development of occupation literacy training. Due to lack of long-term occupation literacy training in view of occupation education in China, if you want to change the idea in the short term there is a certain difficulty, this need from top to bottom gradually to achieve the construction of long-term mechanism of occupation literacy training in higher vocational colleges, from establish occupation literacy training concept foundation. Build a long-term mechanism for training occupation literacy should change from teaching system when Every detail to achieve, occupation literacy education should permeate through each specific teaching process, and to run through the whole education. From the current employment situation of higher vocational students to analyze, is engaged in the specific production or management work, the work usually have the occupation and specialty of the obvious and this requires schools to the actual situation to pay close attention to market in the process of cultivation, according to different industry market areas, different culture and different direction to enterprise occupation occupation skills, this is the science of occupation literacy training. The combination of school enterprise cooperation, is the current higher vocational colleges in the teaching experiment Teaching mode for occupation literacy training point of view, the reform of the teaching mode is very necessary, for the overall development of higher vocational education is also very meaningful, but from the view of practice, the innovative teaching mode that some superficial, in the future development of the work carried out to set up. The scientific literacy training concept fundamentally occupation, the occupation education in occupation education in normalization.

\subsection{The professional quality training into professional teaching}

Occupation education must go through professional education, occupation education is an 
organic part of occupation education, so it must be in the professional teaching process to complete, so professional teaching is the basic approach and platform of occupation quality education. Occupation education in the past, no occupation education the concept into the professional teaching, which requires higher vocational colleges to introduce the concept of occupation literacy training in the teaching process, and to penetrate into the concrete classroom teaching. Occupation literacy training is relatively broad concept, which includes the scope is very broad, in a certain extent test Fit into account and enterprises, which requires schools in teaching activities should be targeted need to consider the enterprise, specific work flow into the conscious goal of the enterprise, let the students in high imitation of a quasi occupation environment to experience, this can greatly stimulate the initiative of students in Higher Vocational Colleges learning, so as to enhance the understanding of the concept of occupation accomplishment. How will the occupation literacy training better into professional teaching, at present in the country is not very mature model can learn, need the whole higher education to explore and try widely.

\subsection{Implement the concept of professional quality education into the curriculum system}

The current occupation education system in China is based on the subject, according to the nature of subjects, content, rules construction of the public basic courses, specialized basic courses to professional courses, professional elective courses system. The traditional curriculum system under the background of classroom teaching in higher vocational colleges is according to from the theory, practice and verification finally, in return to the theory to this end point, the teaching organization to adapt to the new situation in the present is not with the development of higher vocational education, have certain negative effects on Vocational College Students' occupation literacy training. In view of changes in society, occupation literacy training has become an important mission of teaching in Higher Vocational education, This requires a new curriculum system more scientific and reasonable, the concept of occupation education must implement to the new curriculum system of higher vocational education. Higher vocational students should construct occupation literacy training as the core of the new curriculum system, with the market the most extensive job group as a starting point, follow the principle of integration of theory and practice. So, the curriculum system can better adapt to the current situation of the development of vocational education. Higher vocational colleges should abandon the traditional teaching concept, fully aware of the role of market orientation, society and enterprises in the end to what kind of talent will be considered first, knowledge of curriculum system instead of the traditional skill curriculum system, root According to the specific needs of different positions, to carry out targeted more personalized courses, will make higher vocational graduates in the job market more competitive

\subsection{Strengthen the integration of school enterprise culture}

In the traditional concept of our country, schools are places of learning, the culture construction should be based on the academic knowledge, and the enterprise is the production and business establishments, the culture construction should be based on economic interests, although the two are not contradictory, but is also completely unrelated, very to combine together. The characteristics of occupation education is the biggest occupation, so higher vocational colleges should in the construction of campus culture, fully considering the occupation characteristics, the introduction of appropriate corporate culture, and find the best combination of the two cultures, which is very necessary for the cultivation of occupation quality of college students. The enterprise culture is a Business activities gradually formed and widely accepted internal staff humanistic idea, campus culture is the summation of humanistic philosophy is a kind of long-term teaching activities created and the formation of the spiritual level, in essence, the two are the humanistic idea, this is the two most common, which is to find the best combination point between the two to find a basis in theory. The culture is imperceptible for the people affected, although in the short term effect may not be so obvious, but in the long term, occupation accomplishment training should start from building up the cultural atmosphere, so as to integrate occupation literacy training In higher vocational education, it is very meaningful for schools, students and enterprises to organically integrate the two cultures of schools and enterprises and deepen the cooperative relationship between them 


\subsection{Build a new evaluation system}

There are many problems in higher education evaluation standards and evaluation methods in the past, the need for reform to a certain extent, to ensure the overall quality of graduates. The evaluation criteria and evaluation methods in the traditional, only theoretical examination of the curriculum, as long as the examination can pass is deemed to be qualified, this way is too simple no, a good measure of students' occupation ability, but can not reflect the good out of occupation literacy level, from the current development situation, the evaluation criteria and evaluation methods have some obvious backward. To construct a new evaluation system, need further study in the curriculum structure system based on, In order to cultivate the ability of talents as the basic goal, enhance the autonomy of the examination, the scientific nature, content and form of the evaluation of innovation. The appraisal system in occupation literacy training plays a very important role in guiding, to build a more scientific and perfect system of assessment system for higher vocational students the occupation literacy training, have a very important positive significance to enhance the quality of vocational education.

\section{Conclusion}

From the current occupation education practice, although it has achieved some success, but it also exposed some problems, these problems form a great impact on Vocational Students' competitiveness in the job market, the reasons for these problems are many, to solve it with no small difficulty. Vocational students in the process of education, not only to consider the problem of choosing their occupation, entrepreneurial direction should be considered, because of the current economic environment, college students' entrepreneurship is a very good direction. But generally speaking, whether the higher vocational students after entering the community, the choice of jobs, or is Entrepreneurship requires good occupation accomplishment as the foundation support, so in the education stage, must pay attention to their own occupation literacy. For the school, teaching quality is the basis of its own survival, students as the direct object of education, the school can be regarded as the production of products, so the students in the social occupation quality expression will directly reflect the quality of schools, so strengthen the occupation literacy training efforts, is to do it seriously must school.

\section{Acknowledgments}

The author wishes to Acknowledge the support of scientific research funds: Research on The Improvement of Vocational Quality of Vocational Students (J15WC17),Education Department of A Project of Shandong Province Higher Educational Science and Technology Program.

\section{References}

[1] Yang Hong. Research on the cultivation of Higher Vocational Students' professional quality based on employment orientation [D]. Shandong Normal University, 2014.

[2] Yu Xi lead, Li Xiaojuan, Jiao Yang. On the education of professional quality of contemporary youth [J]. Chinese youth research, 2013, (02): 108-112.

[3]. To Yonggang literacy as the core of the occupation of higher vocational colleges moral education mode on the [D]. of Guangdong Polytechnic Normal University, 2016.

[4] Jiang Xinyi. Guangxi Normal University training [D]. occupation quality of students in higher vocational colleges, 2015. 